\title{
A Model of Optimal Growth Strategy
}

\author{
Philippe ASKENAZY (Delta)* \\ Cuong LE VAN (CNRS - CEPREMAP) ${ }^{\dagger}$
}

June 1997

$N^{\circ} 9707$

'DELTA : UMR CNRS - EHESS - ENS.

tThe authors would like to thank Jean-Pierre Laffargue for his very helpful criticisms. 


\title{
A Model of Optimal Growth Strategy
}

\begin{abstract}
In this paper we present an optimal growth model for an open developing country. The latter may choose to produce consumption goods by borrowing on capital markets, or to import consumption goods by investing all its saving on capital markets. We prove that there may be two steady states. An optimal path converges either to zero or to a steady state. That depends on the levels of the initial aid and/or of the debt constraint. We prove also there exists a poverty trap if the time preference is very high.
\end{abstract}

Keywords : Optimal growth model, Euler-Lagrange equations, optimal path, value function, steady states, saddle-point, poverty trap, debt constraint.

JEL Classification numbers : C61, D92, 012.041

$$
-=-=-=-=-=-=-=-
$$

\section{Un Modèle de stratégie de croissance optimale}

RESUME : Dans ce papier, nous présentons un modèle de croissance optimale pour un pays en voie de développement en économie ouverte. Ce pays peut, soit produire des biens de consommation en empruntant, soit importer ces biens en investissant son épargne sur le marché financier. Nous montrons qu'il peut y avoir deux états stationnaires. Tout sentier optimal converge vers zéro ou vers un état stationnaire, en fonction du niveau de l'aide initiale, ou/et du niveau de la contrainte de la dette. Nous montrons aussi qu'il existe une trappe de pauvreté si la préférence pour le présent est très élevée.

Mots clés : Modèle de croissance optimale, équations d'Euler-Lagrange, sentier optimal, fonction valeur, états stationnaires, point-selle, trappe de pauvreté, contrainte de la dette.

JEL numéros de classification : C61, D92, 012, 041 


\section{Introduction}

Most of the Low Developed Countries dispose of a wealth initial stock : resources (renewable or not) in raw materials, international help, embryonic industrialization ...

According to the traditional growth theory, this countries must experience a faster growth in early stages of development, the poorer countries growing faster than richer ones.

Nevertheless, international evidence on growth rates reveals large differences in development patterns among nations (see Azariadis-Drazen (1991) or Barro-Sala-i-Martin (1995)). Some countries manage to sustain high growth rate (the Tigers for example) ; others have persistently low or negative rate of growth. Two similar countries such as Taïwan and the Philippines in the 60's exhibit very different trajectories during three decades : the Taiwan's GDP per capita is $9750 \$$ in 1992 and the Philippines' GDP per capita is only $750 \$$.

One explanation is that persistent differences are due to exogenous factors such as culture, social institutions, demography, market structure. Various works (see Azariadis for a very complete review) study the possibility that this differences could appear among economies with identical structures and give "historical" causes of a model of underdevelopment trap : Consumer impatience, subsistence consumption, human capital externalities, external increasing return in a decentralized economy, demographic transition with endogenous fertility... Expectations may yield multiple equilibrium growth paths (Krugman (1991)). Young (1991) (see also, Klundert-Smulders (1996)) investigates the dynamic effects of international trade with a model in which learning by doing exhibits spillovers across goods : under free trade the Low Developed Countries have rates of technical progress less than those enjoyed under autarky.

Specific economic policies allow to switch over these traps : Taïwan or Singapore imposes very high saving and investment sacrificing the consumption (Young (1995)). These policies are underoptimal for the first generation.

We explore in this paper the relaxation of a fundamental hypothesis in the traditional optimal one-sector growth model for a centralized economy : non-concavity of the production function.

The concavity is a fundamental hypothesis in the standard models ; this condition implies that the optimal intertemporal trajectory is unique and converge towards a steady state. It guarantees that the Euler equation 
and the transversality condition are sufficient and necessary for optimality (Carlson-Haurie-Leizarowitz (1992)).

Nevertheless, the concavity seems to be not relevant for low industrialized countries. The artisanal technology exhibits linear production capital ratio ; the transition to mass production enhances slightly the productivity of labor and capital (organizational, learning by doing, specialization effects ...). At early stages of industrialization, the returns to scale are increasing and the production function becomes concave for higher capital stocks, (see e.g. Azariadis, 1996).

Dechert-Nishimura (1983), using a discrete time model with such production function, show for a country in autarky that the optimal path converges to a steady state only if the initial capital stock is above a critical level ; otherwise it converges to zero. The time preference determines the existence and the level of critical initial capital stock.

In this paper, we extend this analysis to a country which is able to invest on international capital markets. If it borrows, then it will face a debt constraint imposed by the foreign countries. The income could be used for consumption of domestic or foreign goods, for investment in physical capital and for investment on capital markets. For example, the "oil monarchies" choose in the 80's to invest a major part of their revenues in the OECD states and import from these countries consumption goods. Our mathematical approach is different from Dechert-Nishimura (1983) by using a continuous time model.

We find as Dechert-Nishimura for the physical capital, that the wealth is necessarily monotonic and so that cycles are impossible ; nevertheless, along the optimal paths, consumption can first decrease and then increases to a steady state. We exhibit, if the time preference is higher than the real international interest rate, a poverty trap. At early stages of "development", the industrialization may be, or may be not optimal. If the debt constraint is very strong, a country must invest its saving on foreign capital markets and imports consumption goods. If the debt constraint is soft, then the country will borrow and produce consumption goods. We have a result which differs from those stated by Dechert and Nishimura. As in Dechert-Nishimura, in our model, there are two steady states. But under some assumptions they are both optimal. When the debt constraint is hard, or when the initial aid is very low, for a "poor" country, it could be optimal to jump to the low level steady state while a "rich" country converges to the high level steady state, and they have the same technology. There could be no convergence in the levels of development. If the debt constraint is now soft or if the initial aid 
is important, then the poor country may reach the high level steady states. Summing up, there are two ways for helping the Lower Developed Countries : offer a high level of initial aid, or release the debt constraint.

\section{The Model}

We consider a developing country with an initial aid $D_{0}$. At each date $t$, its wealth $W_{t}$ is composed by capital stock $k_{t}$ and saving or foreign debt $S_{t}$. $S_{t}$ generates as returns, $r S_{t}$, with $r$ real interest rate. $k_{t}$ is used to produce consumption goods and capital goods for the next period. The domestic supply is equal to $f\left(k_{t}\right)$. If it is not sufficient to respond to the domestic demand, which is equal to consumption $C_{t}$ and investment $I_{t}$, the country imports $M_{t}$. If the supply is too large in comparison with the domestic demand, then the country will export $M_{t}$.

We have the following balance equation :

$$
C_{t}+I_{t}=f\left(k_{t}\right)+M_{t}
$$

where

$$
I_{t}=\dot{k}_{t}+\delta k_{t}
$$

and

$$
M_{t}=-\dot{S}_{t}+r S_{t}
$$

The consumer maximizes her intertemporal utility function :

$$
\int_{0}^{\infty} u\left(C_{t}\right) e^{-\rho t} d t, \quad \rho>0
$$

under the constraints :

$$
\begin{gathered}
\dot{k}_{t}+C_{t}=f\left(k_{t}\right)+r S_{t}-\delta k_{t}-\dot{S}_{t} \\
S_{t} \geq \bar{S}\left(k_{t}\right), k_{t} \geq 0, \forall t
\end{gathered}
$$

and

$$
k_{0}+S_{0}=D_{0}, \text { with } D_{0} \text { given. }
$$

$\bar{S}\left(k_{t}\right)$ is the debt constraint. It depends on the capital stock $k_{t}$ and, of course, is non positive.

Define $W_{t}=S_{t}+k_{t} . W_{t}$ is the wealth at date $t$. Notice that we implicitly assume perfect substitutability between $S_{t}$ and $k_{t}$. The country could "very quickly" sell capital stock $k_{t}$ and imports consumption goods. 
Barro, Mankiw and Sala-I-Martin (1995), Cohen and Sachs (1986) developed models in which the borrowing constraint $\bar{S}\left(k_{t}\right)$ could not exceed the quantity of physical capital $k_{t}$. Here, we assume $\bar{S}(k)=\bar{s}-\nu k$, with $\nu \in[0,1[$, and $\bar{s} \leq 0$. This formulation is a combination of two interesting cases : i) the debt constraint is constant $(\nu=0)$; ii) it is a fraction of the capital stock $k_{t}$ as in Cohen and Sachs (1986) or Barro, Mankiw and Sala-I-Martin (1995) $(\bar{s}=0)$. The feasible constraint :

$$
\dot{k}_{t}+C_{t}=f\left(k_{t}\right)+r S_{t}-\delta k_{t}-\dot{S}_{t}
$$

becomes :

$$
\dot{W}_{t}+C_{t}=f\left(k_{t}\right)-(\delta+r) k_{t}+r W_{t}
$$

Define

$$
D_{t}=\frac{W_{t}-\bar{s}}{1-\nu}
$$

This constraint is transformed in :

$$
\dot{D}_{t}+\frac{C_{t}}{1-\nu}=\frac{1}{1-\nu} f\left(k_{t}\right)-\frac{\delta+r}{1-\nu} k_{t}+r D_{t}+\frac{r \bar{s}}{1-\nu} .
$$

Define

$$
\begin{gathered}
\widehat{C}_{t}=\frac{C_{t}}{1-\nu} \\
\delta^{\prime}+r=\frac{\delta+r}{1-\nu} \\
\widehat{f}(k)=\frac{1}{1-\nu} f(k) \\
\widehat{u}\left(\widehat{C}_{t}\right)=u\left((1-\nu) \widehat{C}_{t}\right)
\end{gathered}
$$

The problem now becomes :

$$
\max _{\left(\widehat{C}_{t}, D_{t} k_{t}\right)} \int_{0}^{\infty} \widehat{u}\left(\widehat{C}_{t}\right) e^{-\rho t} d t
$$

$$
\begin{array}{ll}
\text { s.t. }: & \dot{D}_{t}+\widehat{C}_{t}=\widehat{f}\left(k_{t}\right)-\left(\delta^{\prime}+r\right) k_{t}+r D_{t}+r \bar{s} /(1-\nu), \\
& \widehat{C}_{t} \geq 0, D_{t} \geq \frac{-\bar{s}}{1-\nu}, D_{t} \geq k_{t} \geq 0 \quad, \quad \forall t
\end{array}
$$

$D_{0}$ is given. 
In order to simplify our exposition we first assume $\bar{s}=\nu=0$. Results obtained in this case will highlight the cases i) $\bar{s}<0$ and $\nu=0$; ii) $\bar{s}=0$ and $\nu>0$, to which is devoted paragraph 5 .

Assume :

(U1) $\quad u$ is strictly increasing ; $u(0)=0 ; u(\infty)=\infty$.

(U2) $\rho>r$.

If $\left(C_{t}^{*}\right)$ is a solution it must be a solution to the following problem :

$$
\begin{aligned}
& \max _{\left(C_{t}, D_{t}\right)} \int_{0}^{\infty} u\left(C_{t}\right) e^{-\rho t} d t \\
& \text { s.t. : } \dot{D}_{t}+C_{t}=\max \left\{f(k)-(\delta+r) k \mid 0 \leq k \leq D_{t}\right\}+r D_{t} \\
& C_{t} \geq 0, \quad D_{t} \geq 0, \quad \forall t \\
& \text { and } D_{0} \text { is given. }
\end{aligned}
$$

Define $\phi(D)=\max \{f(k)-(\delta+r) k \mid k \in[0, D]\}$.

We have therefore the following problem :

$$
\begin{array}{cl} 
& \max _{\left(C_{t}, D_{t}\right)} \int_{0}^{\infty} u\left(C_{t}\right) e^{-\rho t} d t \\
\text { s.t. }: & \dot{D}_{t}+C_{t} \leq \phi\left(D_{t}\right)+r D_{t}, \\
& C_{t} \geq 0, \quad D_{t} \geq 0, \quad \forall t \\
& \text { and } D_{0} \text { is given. }
\end{array}
$$

Assume :

(F1) $f$ is strictly increasing, convex for $k \leq k_{3}$, strictly concave for $k \geq k_{3}, f(0)=0$;

$(F 2)$ There exists $k_{1}^{\prime}, k_{2}^{\prime}$ such that $f$ is continuously differentiable on $\left[0, k_{1}^{\prime}[,] k_{1}^{\prime}, k_{3}[\right.$ and $] k_{3},+\infty[$.

$f^{\prime}(0)<r+\delta$; the left and the right derivatives at $k_{3}$ verify $f_{-}^{\prime}\left(k_{3}\right)>$ $f_{+}^{\prime}\left(k_{3}\right)$. 
$f^{\prime}(\infty)=0 ; f_{-}^{\prime}\left(k_{1}^{\prime}\right)>r+\delta$

Under these assumptions, there exists $k_{1}, k_{2}$ such that $f^{\prime}\left(k_{1}\right)=f^{\prime}\left(k_{2}\right)=$ $r+\delta, 0<k_{1}<k_{1}^{\prime}<k_{2}$.

Assume furthermore :

(F3) $f\left(k_{2}\right)-(r+\delta) k_{2}>0$.

There exists, with this additional $(F 3), \bar{k}, \overline{\bar{k}}$ verifying :

$$
0<\bar{k}<k_{2}<\overline{\bar{k}}
$$

and

$$
f(\bar{k})=(r+\delta) \bar{k}, f(\overline{\bar{k}})=(r+\delta) \overline{\bar{k}}
$$

Let $k(D)$ be defined as the argmax of $\phi$, i.e. :

$$
\phi(D)=f(k(D))-(\delta+r) k(D) .
$$

$k$ and $\phi$ are continuous by the maximum theorem. It is straightforward to check that :

i) $D=\bar{k} \Rightarrow k(D)=\{0, \bar{k}\}$ and $\phi(D)=0$.

ii) $0 \leq D<\bar{k} \Rightarrow k(D)=0$ and $\phi(D)=0$.

iii) $\bar{k}<D \leq k_{2} \Rightarrow k(D)=D$ and $\phi(D)=f(D)-(r+\delta) D$.

iv) $k_{2}<D \Rightarrow k(D)=k_{2}$ and $\phi(D)=f\left(k_{2}\right)-(\delta+r) k_{2}$.

$\phi$ is piecewise continuously differentiable.

\section{Existence of Solutions}

\subsection{Feasible paths}

$\left(\widetilde{C}_{t}, \widetilde{D}_{t}\right)$ is said to be feasible from $D_{0}$ if $\widetilde{C}_{t}$ belongs to $L^{1}\left(e^{-\rho t}\right), \widetilde{D}_{t}$ belongs also to $L^{1}\left(e^{-\rho t}\right)$

$$
\begin{gathered}
\forall t, \widetilde{C}_{t}+\dot{\widetilde{D}}_{t} \leq \phi\left(\widetilde{D}_{t}\right)+r \widetilde{D}_{t} \\
\widetilde{C}_{t} \geq 0, \widetilde{D}_{t} \geq 0 ; \text { and } \widetilde{D}_{0}=D_{0} .
\end{gathered}
$$


Proposition 1 There exists $M_{1}, M_{2}$ such that:

$$
\int_{0}^{\infty} C_{t} e^{-\rho t} d t \leq M_{1}, \int_{0}^{\infty} D_{t} e^{-\rho t} d t \leq M_{2}
$$

for every feasible $\left(C_{t}, D_{t}\right)$ from $D_{0}$.

Proof. From (1) and the properties of $\phi$, one has :

$$
\dot{D}_{t} \leq A+r D_{t}, \text { with } A=f\left(k_{2}\right)-(r+\delta) k_{2} .
$$

Hence

$$
D_{t}+\frac{A}{r} \leq \frac{1}{r}\left(A+D_{0} r\right) e^{r t}
$$

and

$$
\int_{0}^{\infty} D_{t} e^{-\rho t} d t \leq \frac{A}{r} \int_{0}^{\infty} e^{(r-\rho) t} d t+D_{0} \int_{0}^{\infty} e^{(r-\rho) t} d t=M_{2}
$$

From this inequality one deduces that $\lim _{t \rightarrow \infty} D_{t} e^{-\rho t}=0$. Again, using (1), one gets :

$$
\int_{0}^{\infty} C_{t} e^{-\rho t} d t+\int_{0}^{\infty} \dot{D} e^{-\rho t} d t \leq A \int_{0}^{\infty} e^{-\rho t} d t+r \int_{0}^{\infty} D_{t} e^{-\rho t} d t
$$

But

$$
\int_{0}^{\infty} \dot{D}_{t} e^{-\rho t} d t=-D_{0}+\rho \int_{0}^{\infty} D_{t} e^{-\rho t} d t
$$

Hence

$$
\int_{0}^{\infty} C_{t} e^{-\rho t} d t \leq \frac{A}{\rho}+D_{0}=M_{1}
$$

\subsection{Existence of solutions in the class of bounded func- tions}

Assume moreover :

(U3) $u$ is continuously differentiable.

Lemma 1 Define $U(C)=\int_{0}^{\infty} u\left(C_{t}\right) e^{-\rho t} d t$, where $C \in L_{+}^{1}\left(e^{-\rho t}\right)$. $U$ is continuous on $L_{+}^{1}\left(e^{-\rho t}\right)$ and, hence, is $\sigma\left(L^{1}, L^{\infty}\right)$ - upper semi-continuous (u.s.c.). 
Proof. We will note, to make short, $L^{1}$ (or $\left.L_{+}^{1}\right)$ instead of $L^{1}\left(e^{-\rho t}\right)$ (or $\left.L_{+}^{1}\left(e^{-\rho t}\right)\right)$.

Let $\left\{C^{n}\right\}$ be a sequence in $L_{+}^{1}$ converging to $C$ in $L^{1}$. We have, for any $a>0$,

$0 \leq \int_{0}^{\infty} u\left(C_{t}^{n}\right) e^{-\rho t} d t \leq \int_{0}^{\infty}\left(u(a)-a u^{\prime}(a)\right) e^{-\rho t} d t+u^{\prime}(a) \int_{0}^{\infty} C_{t}^{n} e^{-\rho t} d t \leq M$

Let $\alpha$ be a cluster point of $\int_{0}^{\infty} u\left(C_{t}^{n}\right) e^{-\rho t} d t$. There exists a subsequence $\left\{C^{\nu}\right\}, C^{\nu} \stackrel{L^{1}}{\rightarrow} C, C^{\nu} \rightarrow C$ pointwise and $C^{\nu} \leq g$ for some $g \in L^{1}$, and $\int_{0}^{\infty} u\left(C_{t}^{\nu}\right) e^{-\rho t} d t \rightarrow \alpha$.

$$
\begin{aligned}
u\left(C_{t}^{\nu}\right) & \leq u(a)-u^{\prime}(a) a+u^{\prime}(a) C_{t}^{\nu} \\
& \leq u(a)-u^{\prime}(a) a+u^{\prime}(a) g
\end{aligned}
$$

From Lebesgue Theorem, $\alpha=\int_{0}^{\infty} u\left(C_{t}\right) e^{-\rho t} d t$. Hence, $\int_{0}^{\infty} u\left(C_{t}^{\nu}\right) e^{-\rho t} d t \rightarrow$ $\int_{0}^{\infty} u\left(C_{t}\right) e^{-\rho t} d t . U$ is continuous in $L_{+}^{1}$. Since it is concave, it is weakly u.s.c.

Proposition 2 Let $\Gamma$ denote the set of feasible $C_{t}$ from $D_{0}$. Let $g \geq 0$ be a function in $L^{1}$, and $G=\{x \mid x \leq g\}$. Then there exists a solution in $\Gamma \cap G$.

Proof. As we have shown in the proof of Lemma 1, there exists some $M$ such that:

$$
0 \leq U(C) \leq M, \quad \forall C \in \Gamma .
$$

Let $\mu=\sup \{U(C) ; C \in \Gamma \cap G\}$. There exists a sequence $\left\{C^{n}\right\} \subset \Gamma \cap G$ such that $U\left(C^{n}\right) \rightarrow \mu$. Without loss of generality, we assume that $C^{n}+\dot{D}^{n}=$ $\phi\left(D^{n}\right)+r D^{n}, \forall n$. The sequence $\left\{C^{n}\right\}$ verifies Dunford-Pettis criterion since $0 \leq C^{n} \leq g, \forall n$, and hence $\sigma\left(L^{1}, L^{\infty}\right)$ relatively compact. We may assume $C^{n} \rightarrow \bar{C}, \phi\left(D^{n}\right) \rightarrow \psi, D^{n} \rightarrow D$ with $\sigma\left(L^{1}, L^{\infty}\right)$. Hence $\dot{D}^{n} \rightarrow x$ with $\sigma\left(L^{1}, L^{\infty}\right)$.

Define $\widehat{D}(t)=\int_{0}^{t} x(u) d u+D_{0}$. Then, we have

$$
\int_{0}^{t} \dot{D}^{n}(u) d u \rightarrow \int_{0}^{t} x(u) d u, \quad \forall t
$$


i.e.

$$
D^{n}(t) \rightarrow \widehat{D}(t), \quad \forall t
$$

From Lebesgue Theorem, $D^{n} \rightarrow \widehat{D}$ in $L^{1}$ and therefore, $\widehat{D}=D$. Moreover $\phi\left(D^{n}\right) \rightarrow \phi(D)$ in $L^{1}$ and $x=\dot{D}$.

Since, $\forall n, C^{n}+\dot{D}^{n}=\phi\left(D^{n}\right)+r D^{n}$, one gets $C+\dot{D}=\phi(D)+r D$, and $C \in \Gamma$.

We prove now $C \in G$. Indeed, if $C(t)>g(t)$ for some $t \in I$ with $\int_{I} d t>0$, then

$$
\int_{I} C_{t} e^{-\rho t} d t>\int_{I} g(t) e^{-\rho t} d t, \quad \text { in contradiction }
$$

with

and

$$
\int_{I} C^{n}(t) e^{-\rho t} d t \leq \int_{I} g(t) e^{-\rho t} d t, \quad \forall n
$$

$$
\int_{I} C^{n}(t) e^{-\rho t} d t \rightarrow \int_{I} C_{t} e^{-\rho t} d t
$$

Now, since, $U$ is weakly continuous (Lemma 1 ), we have

$$
\mu \leq U(C) \text {, and hence } \mu=U(C) .
$$

\section{Characterization and Properties of Opti- mal Paths}

In this paragraph we first show that in our model there would be three steady states $k_{1}^{s}<k_{2}^{s}$ and trivial one $k_{3}^{s}=0$. We then prove that the optimal path may converge to zero (the proverty trap), or may reach $k_{1}^{s}$, or converge to $k_{2}^{s}$. The technics of the proof differs greatly from the usual ones in neoclassical models which are based on the concavity of the utility function and of the production function. Since the technology in our model is not concave, we could not apply these methods. The key tool is the monotonicity of the optimal paths, property which will be proved in this paragraph.

Let us define the value function :

$$
\begin{aligned}
& V\left(D_{0}, 0\right)=\sup _{C_{t}} \int_{0}^{\infty} u\left(C_{t}\right) e^{-\rho t} d t \\
& \left\{\begin{array}{l}
C_{t}+\dot{D}_{t}=\phi\left(D_{t}\right)+r D_{t}, \quad \forall t \\
C_{t} \geq 0, D_{t} \geq 0, \quad \forall t \\
D_{0}>0 \text { is given. }
\end{array}\right.
\end{aligned}
$$


We assume in this section that every optimal solution is piecewise continuous and the associated $D_{t}$ is piecewise $C^{1}$.

Proposition $3 V(., 0)$ is non decreasing.

Proof. See appendix.

Proposition 4 Let $C_{t}$ be a solution and $D_{t}$ the associated path. Let $t_{0}$ be fixed. Then $V(., 0)$ is continuous at $D\left(t_{0}\right)$.

Proof. See appendix.

Assume moreover :

$(U 4): u^{\prime}(0)=+\infty$ (Inada condition)

We then have :

Proposition 5 Let $C_{t}$ be a solution and $D_{t}$ be the associated path. Let $T, T^{\prime}$ $\left(T<T^{\prime}\right)$ be such that $\phi^{\prime}(x)$ is continuous for every $x$ in a neighborhood of $\left\{D(t) ; t \in\left[T, T^{\prime}\right]\right\}$. Then we have for $t \in\left[T, T^{\prime}\right]$ Euler-Lagrange equation :

$(E-L) \quad-\frac{d}{d t}\left(u^{\prime}\left(C_{t}\right) e^{-\rho t}\right)=e^{-\rho t} u^{\prime}\left(C_{t}\right)\left(\phi^{\prime}\left(D_{t}\right)+r\right)$

and $C, D$ are continuous on $\left[T, T^{\prime}\right]$.

Proof. See appendix.

Corollary 1 Let $T, T^{\prime}\left(T<T^{\prime}\right)$ be such that $\phi^{\prime}(x)$ is continuous for $x \in$ $\left\{D(t) \mid t \in\left[T, T^{\prime}\right]\right\}$, where $D_{t}$ is the associated path with the optimal path $C_{t}$. Then $D$ is monotonic on $\left[T, T^{\prime}\right]$.

Proof. Assume for simplicity that $D\left(T_{B}-\varepsilon_{0}\right)=D\left(T_{B}+\varepsilon_{0}^{\prime}\right)$ and $D$ is decreasing from $T_{B}-\varepsilon_{0}$ to $T_{B}$ and increasing from $T_{B}$ to $T_{B}+\varepsilon_{0}^{\prime}$. For every $\left.\varepsilon \in] 0, \varepsilon_{0}\right]$, there exists a unique $\left.\left.\varepsilon^{\prime} \in\right] 0, \varepsilon_{0}^{\prime}\right]$ such that $D\left(T_{B}-\varepsilon\right)=D\left(T_{B}+\varepsilon^{\prime}\right)$.

From the maximum principle one has :

$$
\begin{aligned}
e^{-\rho\left(T_{B}-\varepsilon\right)} V\left(D\left(T_{B}-\varepsilon\right), 0\right) & =V\left(D\left(T_{B}-\varepsilon\right), T_{B}-\varepsilon\right) \\
& =\int_{T_{B}-\varepsilon}^{T_{B}+\varepsilon^{\prime}} e^{-\rho t} u\left(C_{t}\right) d t+e^{-\rho\left(T_{B}+\varepsilon^{\prime}\right)} V\left(D\left(T_{B}+\varepsilon^{\prime}\right), 0\right) .
\end{aligned}
$$


Hence

$$
V\left(D\left(T_{B}-\varepsilon\right), 0\right) e^{\rho\left(\varepsilon^{\prime}-\varepsilon\right)}=\int_{T_{B}-\varepsilon}^{T_{B}+\varepsilon^{\prime}} e^{-\rho t} u\left(C_{t}\right) d t .
$$

When $\varepsilon \rightarrow 0$, one has $\varepsilon^{\prime} \rightarrow 0$. Since

$$
V\left(D\left(T_{B}-\varepsilon\right), 0\right) \frac{e^{\rho\left(\varepsilon^{\prime}-\varepsilon\right)}}{\varepsilon^{\prime}-\varepsilon}=\frac{1}{\varepsilon^{\prime}-\varepsilon} \int_{T_{B}-\varepsilon}^{T_{B}+\varepsilon^{\prime}} e^{-\rho t} u\left(C_{t}\right) d t
$$

one gets, since $V(., 0)$ is continuous on the path $D_{t}$ (proposition 4), and $C$ is continuous (proposition 5),

$$
\begin{aligned}
V\left(D_{B}, 0\right) & =u\left(C\left(T_{B}\right)\right) / \rho \\
& =\int_{0}^{+\infty} u\left(C\left(T_{B}\right)\right) e^{-\rho t} d t .
\end{aligned}
$$

The path $\widetilde{C}(t)=C\left(T_{B}\right), \forall t$ is feasible since $\dot{D}\left(T_{B}\right)=0$ and $C\left(T_{B}\right)=$ $\phi\left(D\left(T_{B}\right)\right)+r D\left(T_{B}\right)$. It is therefore optimal for the problem with $D_{B}$ as initial data. Since $\widetilde{C}(t)$ is strictly positive, it verifies Euler-Lagrange equation. But this is impossible. We obtain a contradiction.

Remark 1 In our case, we obtain the monotonicity of $D_{t}$ under weaker conditions than in Léonard-Van Long (1992) who assume that $V$ is differentiable with the respect to the initial date.

The aim of the following propositions is to show that : a) when $D_{0}$ is small then the country will never produce consumption goods, imports them in order to satisfy its consumption, and will be "under-developed" for ever (proposition 6), and b) if a country prefers strongly the present to the future then in the long term it will be "under-developed" (proposition 7).

Assume furthermore

(U5) $u$ is twice continously differentiable.

Proposition 6 Let $\bar{k}$ be defined as in section 1, i.e.,

$$
f(\bar{k})=(r+\delta) \bar{k}
$$

There exists $\bar{D}_{0}<\bar{k}$ such that, if $D_{0} \leq \bar{D}_{0}$, then $C_{t} \rightarrow 0$ and $D_{t} \rightarrow 0$ when $t \rightarrow+\infty$, where $C_{t}$ is the optimal path, and $D_{t}$ is the associated path. 
Proof. Consider Euler-Lagrange equation. Assume there exists $T$ such that $D(T)=\bar{k}$. From corollary $1, D$ increases from $D_{0}$ to $\bar{k} ; \phi\left(D_{t}\right)=0$ for $\dot{t} \in[0, T]$. We obtain for $t \in[0, T]$ :

$$
u^{\prime}\left(C_{t}\right)=u^{\prime}\left(C_{0}\right) e^{(\rho-r) t}
$$

From :

$$
C_{t}+\dot{D}_{t}=r D_{t} \quad \text { for } \quad t \in[0, T]
$$

we have

$$
D_{t}=D_{0} e^{r t}-e^{r t} \int_{0}^{t} C_{s} e^{-r s} d s
$$

Since $D(T)=\bar{k}$, we have

$$
\bar{k}=D_{0} e^{r T}-e^{r T} \int_{0}^{T} C_{s} e^{-r s} d s
$$

Consider (3) as a relation giving $C_{0}$ as function of $D_{0}$ and $T$. Let us fix $D_{0}$. Differentiating (3), one gets :

$$
0=\dot{D}_{T} d T-e^{r T}\left(\int_{0}^{T} \frac{\partial C_{s}}{\partial C_{0}} e^{-r s} d s\right) d C_{0}
$$

But

$$
\frac{\partial C_{s}}{\partial C_{0}}=\frac{u^{\prime \prime}\left(C_{0}\right)}{u^{\prime \prime}\left(C_{s}\right)} e^{(\rho-r) s} \quad(\text { from }(2))
$$

Hence

$$
\frac{\partial C_{0}}{\partial T}=\frac{\dot{D}_{T} e^{-r T}}{\int_{0}^{T} \frac{u^{\prime \prime}\left(C_{0}\right)}{u^{\prime \prime}\left(C_{s}\right)} e^{(\rho-2 r) s} d s}
$$

Define

$$
W(T)=\int_{0}^{T} u\left(C_{t}\right) e^{-\rho t} d t
$$

We have

$$
V\left(D_{0}, 0\right)=W(T)+e^{-\rho T} V(\bar{k}, 0) .
$$

Hence, $T$ must maximize the function $W(t)+e^{-\rho t} V(\bar{k}, 0)$. Then

$$
W^{\prime}(T)=\rho e^{-\rho T} V(\bar{k}, 0)
$$

(This is just the transversality condition of a problem with free -end-point and scrap value function; see Léonard and Van Long, 1992). 
We have :

$$
\begin{aligned}
W^{\prime}(T) & =u\left(C_{T}\right) e^{-\rho T}+\left[\int_{0}^{T} u^{\prime}\left(C_{t}\right) \frac{\partial C_{t}}{\partial C_{0}} e^{-\rho t} d t\right] \frac{\partial C_{0}}{\partial T} \\
& =u\left(C_{T}\right) e^{-\rho T}+\left[\int_{0}^{T} u^{\prime}\left(C_{0}\right) \frac{u^{\prime \prime}\left(C_{0}\right)}{u^{\prime \prime}\left(C_{t}\right)} e^{(\rho-2 r) t} d t\right] \frac{\dot{D}_{T} e^{-r T}}{\int_{0}^{T} \frac{u^{\prime \prime}\left(C_{0}\right)}{u^{\prime \prime}\left(C_{t}\right)} e^{(\rho-2 r) t} d t} \\
& =u\left(C_{T}\right) e^{-\rho T}+u^{\prime}\left(C_{0}\right) \dot{D}_{T} e^{-r T}
\end{aligned}
$$

Using (4) one gets :

$$
\begin{aligned}
\rho V(\bar{k}, 0) & =u\left(C_{T}\right)+u^{\prime}\left(C_{0}\right) \dot{D}_{T} e^{(\rho-r) T} \\
& \geq u^{\prime}\left(C_{0}\right) \dot{D}_{T} e^{(\rho-r) T}
\end{aligned}
$$

If $\dot{D}_{t}>0$ on $[0, T]$, we have $\dot{D}_{T}=\bar{k}-C_{T}>\bar{k}-C_{0} \geq \bar{k}-r D_{0}$, because $C_{0} \leq r D_{0}$ since $\dot{D}(0) \geq 0$.

Hence, if $D_{0}$ is such that $\bar{k}-r D_{0}>0$, then

$$
e^{(\rho-r) T} \leq \frac{\rho V(\bar{k}, 0)}{\left(\bar{k}-r D_{0}\right) u^{\prime}\left(r D_{0}\right)}
$$

From (U4), we obtain a contradiction if $D_{0}$ is small enough. Summing up, if $D_{0}$ is small, the path $D(t)$ could not reach $\vec{k}$. From corollary $1, D(t)$ must be decreasing. Since $C_{t}+\dot{D}_{t}=r D_{t}$, we have

$$
D_{t} \leq \frac{C_{t}}{r}, \forall t
$$

From (2), $u^{\prime}\left(C_{t}\right) \rightarrow+\infty$ when $t \rightarrow+\infty$, i.e. $C_{t} \rightarrow 0$ (Inada condition). Hence $D_{t}$ converges also to 0 .

Proposition 7 Assume $\rho>f_{+}^{\prime}\left(k_{3}\right)-\delta$. Then for any $D_{0}$, the optimal path $\left(C_{t}, D_{t}\right)$ converge to 0 .

Proof. Consider Euler-Lagrange equation :

$$
\begin{aligned}
-\frac{d}{d t}\left(u^{\prime}\left(C_{t}\right) e^{-\rho t}\right) & =e^{-\rho t} u^{\prime}\left(C_{t}\right)\left(\phi^{\prime}\left(D_{t}\right)+r\right) \\
& <e^{-\rho t} u^{\prime}\left(C_{t}\right)\left(f_{+}^{\prime}\left(k_{3}\right)-\delta\right) .
\end{aligned}
$$


Hence

$$
\log \frac{u^{\prime}\left(C_{t}\right) e^{-\rho t}}{u^{\prime}\left(C_{0}\right)}>\left(\delta-f_{+}^{\prime}\left(k_{3}\right)\right) t
$$

or

$$
u^{\prime}\left(C_{t}\right)>u^{\prime}\left(C_{0}\right) e^{\left(\rho+\delta-f_{+}^{\prime}\left(k_{3}\right)\right) t} .
$$

Therefore, $u^{\prime}\left(C_{t}\right) \rightarrow+\infty$ and $C_{t} \rightarrow 0$.

Let $D_{t}$ be the associated path. We first prove there exists a sequence $\left\{D_{t_{n}}\right\}$ converging to 0 . Assume the contrary, $D_{t} \geq \alpha>0, \forall t$. We know that:

$$
\forall \varepsilon>0, \quad \exists T, \quad \forall t \geq T, C_{t} \leq \varepsilon .
$$

Define

$$
\begin{array}{ll}
\widetilde{C}(t)=C(t) & \text { for } \quad t<T \\
\widetilde{C}(t)=\varepsilon & \text { for } t \geq T \\
\widetilde{D}(t)=D(t) & \text { for } \quad t<T
\end{array}
$$

and $\widetilde{D}$ verifies for $t \geq T$

$$
\begin{array}{ll}
\dot{\widetilde{D}}_{t} & =\phi\left(\widetilde{D}_{t}\right)+r \widetilde{D}_{t}-\varepsilon \\
\widetilde{D}(T) & =D(T) \geq \alpha
\end{array}
$$

Choose $\varepsilon<r \alpha$.

In some interval $\left[T, T^{\prime}\right]$, we have $r \widetilde{D}_{t}-\varepsilon \geq 0$. Hence

$$
\left.\widetilde{D}(t)>\widetilde{D}(T), \forall t \in] T, T^{\prime}\right]
$$

Let $\bar{T}$ be the maximum $T^{\prime}$ such that $\left.\left.r \widetilde{D}_{t}-\varepsilon \geq 0, \forall t \in\right] T, \bar{T}\right]$. Assume $\bar{T}<+\infty$. One has

$$
\widetilde{D}(t)>\widetilde{D}(T), \forall t \in] T, \bar{T}]
$$

In particular $\widetilde{D}(\bar{T})>\widetilde{D}(T) \geqslant \alpha$.

Since $\widetilde{D}$ is continuous, there exists $\bar{T}^{\prime}>\bar{T}$ such that $r \widetilde{D}_{t}-\varepsilon \geq 0$ for $t \in\left[\bar{T}, \bar{T}^{\prime}\right]:$ a contradiction. Hence

$$
\widetilde{D}(t)>D(T) \geq \alpha, \forall t>T .
$$

The path $\widetilde{C}_{t}$ is therefore feasible from $D_{0}$, and $U(\widetilde{C})>U(C)$ : a contradiction.

There exists a sequence $D_{t_{1}}, \ldots, D_{t_{n}}$ converging to 0 . For $n$ sufficiently large $D_{t_{n}} \leq \bar{D}_{0}$. From proposition $6, D_{t}$ must converge to 0 .

Assume moreover :

(U6) : $\rho<f_{+}^{\prime}\left(k_{3}\right)-\delta$ 
(U7) : $\lim _{c \rightarrow+0} \frac{u^{\prime}(C)}{u^{\prime \prime}(C)}=0$

$(F 4): \quad f\left(k_{3}\right) / k_{3}>f_{+}^{\prime}\left(k_{3}\right)$

Define a steady state $\left(c^{s}, k^{s}\right)$ as follows :

$$
\begin{gathered}
f^{\prime}\left(k^{s}\right)=\rho+\delta \\
c^{s}=f\left(k^{s}\right)-\delta k^{s} .
\end{gathered}
$$

Proposition 8 If $f_{+}^{\prime}(\bar{k})>\rho+\delta$, then there exists a unique steady state $\left(c_{2}^{s}, k_{2}^{s}\right)$ with $k_{3}<k_{2}^{s}<k_{2}$.

If $f_{+}^{\prime}(\bar{k}) \leq \rho+\delta$, then there exists two steady states $\left(c_{1}^{s}, k_{1}^{s}\right),\left(c_{2}^{s}, k_{2}^{s}\right)$ with

$$
\bar{k} \leq k_{1}^{s}<k_{3}<k_{2}^{s}<k_{2}
$$

Proof. Since $f$ is convex on $\left[\bar{k}, k_{3}\right]$, if $f_{+}^{\prime}(\bar{k})>\rho+\delta$, then $f^{\prime}(x)>\rho+\delta$, $\forall x \in\left[\bar{k}, k_{3}\right]$. Then there exists a unique steady state.

If $f_{+}^{\prime}(\bar{k}) \leq \rho+\delta$, since $f_{-}^{\prime}\left(k_{3}\right)>\frac{f\left(k_{3}\right)}{k_{3}}>f_{+}^{\prime}\left(k_{3}\right)>\rho+\delta$ by $(U 6)$ and ( $(F 4)$, there exists a steady state $\left(c_{1}^{s}, k_{1}^{s}\right)$ with $\bar{k} \leq k_{1}^{s}<k_{3}$.

\section{(Insert figure 1)}

Proposition 9 Let $k_{3} \leq D_{0}<k_{2}^{s}$. Then there exists an optimal path $\left(C_{t}, k_{t}\right)$ converging to $\left(c_{2}^{s}, k_{2}^{s}\right)$.

Proof. Consider the system

$$
\left\{\begin{array}{l}
\frac{d}{d t}\left(-u^{\prime}\left(C_{t}\right) e^{-\rho t}\right)=u^{\prime}\left(C_{t}\right) e^{-\rho t}\left(f^{\prime}\left(D_{t}\right)-\delta\right) \\
\dot{D}_{t}=f\left(D_{t}\right)-\delta D_{t}-C_{t} \\
D_{0} \text { is given in }\left[k_{3}, k^{s}\right] .
\end{array}\right.
$$

The first equation is equivalent to :

$$
\dot{C}_{t}=\frac{u^{\prime}\left(C_{t}\right)}{u^{\prime \prime}\left(C_{t}\right)}\left(\delta+\rho-f^{\prime}\left(D_{t}\right)\right)
$$


It is straightforward to check that $k_{2}^{s}$ is a saddle-point of this system. There exists a stable manifold $\left(D_{t}, C_{t}\right)$. It could not intersect the axis $C=0$ at a point $k_{0}>k_{3}$, because, in that case, under $(U 7)$ the system will have two solutions starting from $\left(k_{0}, 0\right)$ : the stable manifold, and the half-line $\left(D_{t}, 0\right)$ where $D_{t}$ is solution to $\dot{D}_{t}=f\left(D_{t}\right)-\delta D_{t} ; D(0)=k_{0}$.

Hence, the stable manifold will intersect the axis $D=k_{3}$ at a point $C_{0} \geq 0$. Then, for every $D_{0} \in\left[k_{3}, k^{s}\right]$, there exists $C_{0} \geq 0 \mathrm{such}$ that $\left(D_{0}, C_{0}\right)$ belongs to the stable manifold.

We prove now the solution $\left(D^{*}, C^{*}\right)$ of the system above with initial data $\left(D_{0}, C_{0}\right)$ is the optimal solution.

Let $\left(C_{t}\right)$ be a feasible consumption path from $D_{0}$ and

$$
\begin{aligned}
\Delta_{T} & =\int_{0}^{T}\left(u\left(C_{t}^{*}\right)-u\left(C_{t}\right)\right) e^{-\rho t} d t \\
& =\int_{0}^{T}\left[u\left(\phi\left(D_{t}^{*}\right)+r D_{t}^{*}-\dot{D}_{t}^{*}\right)-u\left(\phi\left(D_{t}\right)+r D_{t}-\dot{D}_{t}\right)\right] e^{-\rho t} d t
\end{aligned}
$$

We have :

$$
\Delta_{T} \geq \int_{0}^{T} u^{\prime}\left(C_{t}^{*}\right)\left[\phi\left(D_{t}^{*}\right)+r D_{t}^{*}-\dot{D}_{t}^{*}-\phi\left(D_{t}\right)-r D_{t}+\dot{D}_{t}\right] e^{-\rho t} d t
$$

Recall that

$$
\phi\left(D_{t}^{*}\right)=f\left(D_{t}^{*}\right)-(r+\delta) D_{t}^{*} \quad \text { since } \quad D_{t}^{*} \geq \bar{k}
$$

Now,

$$
f\left(D_{t}^{*}\right)-f\left(k_{3}\right) \geq f^{\prime}\left(D_{t}^{*}\right)\left(D_{t}^{*}-k_{3}\right) .
$$

If $f$ is convex at $D_{t}$ then, by $(F 4)$

$$
\frac{f\left(k_{3}\right)-f\left(D_{t}\right)}{k_{3}-D_{t}} \geq \frac{f\left(k_{3}\right)}{k_{3}}>f_{+}^{\prime}\left(k_{3}\right) \geq f^{\prime}\left(D_{t}^{*}\right)
$$

and hence

$$
f\left(D_{t}^{*}\right)-f\left(D_{t}\right) \geq f^{\prime}\left(D_{t}^{*}\right)\left(D_{t}^{*}-D_{t}\right)
$$

Summing up :

$$
\Delta_{T} \geq \int_{0}^{T} u^{\prime}\left(C_{t}^{*}\right)\left[\left(f^{\prime}\left(D_{t}^{*}\right)-\delta\right)\left(D_{t}^{*}-D_{t}\right)-\left(\dot{D}_{t}^{*}-D_{t}\right)\right] e^{-\rho t} d t .
$$

Since we have Euler-Lagrange equation :

$$
\frac{d}{d t}\left(-u^{\prime}\left(C_{t}^{*}\right) e^{-\rho t}\right)=u^{\prime}\left(C_{t}^{*}\right) e^{-\rho t}\left(f^{\prime}\left(D_{t}^{*}\right)-\delta\right)
$$


we obtain

$$
\Delta_{T} \geq-u^{\prime}\left(C_{t}^{*}\right)\left(D_{t}^{*}-D_{t}\right) e^{-\rho t} d t \geq-u^{\prime}\left(C_{T}^{*}\right) D_{T}^{*} e^{-\rho t} \rightarrow 0 .
$$

Let us consider again the dynamical system :

$$
\left\{\begin{array}{l}
\frac{d C}{d t}=\frac{u^{\prime}(C)}{u^{\prime \prime}(C)}\left(\rho-r-\phi^{\prime}(D)\right) \\
\frac{d D}{d t}=\phi(D)+r D-C
\end{array}\right.
$$

The following phase-diagram is in figure 1.

The purpose of proposition 10 is to obtain corollary 2 stating that the low level steady state $k_{1}^{s}$ may be optimal. This result is new : in Dechert and Nishimura (1983), the low level steady state is not optimal. We may observe also that in many papers on economic growth, their authors do not demonstrate that the steady states of their models are, or are not, optimal.

Proposition 10 Assume $u(C)=\frac{C^{\sigma}}{\sigma}$ with $\left.\sigma \in\right] 0,1[$, and for $k \in[\bar{k}, \bar{D}]$ with $\bar{D}<k_{1}^{s}$, we have $f(k)=\lambda(k-\bar{k})+f(\bar{k})$ where $\lambda$ verifies $\delta<\lambda, r<\lambda<\rho+\delta$.

If $\rho<1-\sigma+\sigma(\lambda-\delta)$, then the optimal path $\left(D_{t}\right)$ starting from $\bar{D}$ will be nondecreasing if $\bar{D}$ is large enough.

Proof. See appendix.

Corollary 2 Assume as in proposition 10. If $\bar{D}$ and $k_{3}$ are large enough, then $k_{1}^{s}$ is an optimal steady state.

Proof. First $\left(k_{1}^{s}\right)$ verifies Euler-Lagrange equation. Consider an optimal path $\left(D_{t}\right)$ starting from $k_{1}^{s}$. If $k_{3}$ is large enough then the optimal path could not reach $k_{3}$. In this case it will be non increasing (corollary 1). Assume it could reach $\bar{D}$. But from proposition 10 if $\bar{D}$ is large enough the optimal path starting from $\bar{D}$ must be non decreasing. We have a contradiction by corollary 1 and by the fact that $\bar{D}$ is not a steady state. Hence the optimal path starting from $k_{1}^{s}$ will be $\left(k_{1}^{s}\right)$.

We now summarize our results in the following theorem.

Theorem 1 Assume $(U 1), \ldots,(U 7),(F 1), \ldots,(F 4)$. Let $0 \leq D_{0} \leq k_{2}^{s}$. 
1. If there exists two steady state $\left(c_{1}^{s}, k_{2}^{s}\right),\left(c_{2}^{s}, k_{2}^{s}\right)$, then

a) either the optimal path $\left(C_{t}, k_{t}\right)$ converges to $\left(c_{2}^{s}, k_{2}^{s}\right)$,

b) or there exists $T$, such that $\left(C_{t}, k_{t}\right)=\left(c_{1}^{s}, k_{1}^{s}\right), \forall t \geq T$,

c) or the optimal path converges to 0 .

2. If there exists one steady $\left(c_{2}^{s}, k_{2}^{s}\right)$ then

a) either the optimal converges to $\left(c_{2}^{s}, k_{2}^{s}\right)$,

b) or it converges to 0 .

\section{Proof.}

1. Assume we have two steady states. If $D_{0} \geq k_{3}$, then the optimal converges to $\left(c_{2}^{s}, k_{2}^{s}\right)$ from proposition 8 .

If $D_{0}=k_{1}^{s}$, we may have $\left(c_{1}^{s}, k_{1}^{s}\right)$ as optimal path.

If $k_{1}^{s}<D_{0}<k_{3}$. We assume first the optimal $D_{t}$ increasing. If $D_{t}$ reaches $k_{3}$ at some date $T$, we take $C(T)=c_{3}$ such that $\left(c_{3}, k_{3}\right)$ belongs to the stable manifold. $\left(C_{t}, D_{t}\right)$ converges therefore to $\left(c_{2}^{s}, k_{2}^{s}\right)$. Assume that $D_{t}$ is increasing and could not reach $k_{3}$.

Consider the dynamic equation of $C_{t}$ :

$$
-\frac{d}{d t}\left(u^{\prime}\left(C_{t}\right) e^{-\rho t}\right)=e^{-\rho t} u^{\prime}\left(C_{t}\right)\left(f^{\prime}\left(D_{t}\right)-\delta\right)
$$

We have

$$
u^{\prime}\left(C_{t}\right) e^{-\rho t}=u^{\prime}\left(C_{0}\right) \exp \left(-\int_{0}^{t}\left(f^{\prime}\left(D_{s}\right)-\delta\right) d s\right)
$$

i.e.

$$
u^{\prime}\left(C_{t}\right)=u^{\prime}\left(C_{0}\right) \exp \left(\int_{0}^{t}\left(\rho+\delta-f^{\prime}\left(D_{s}\right)\right) d s\right)
$$

Hence

$$
u^{\prime}\left(C_{t}\right)<u^{\prime}\left(C_{0}\right) e^{\left(\rho+\delta-f^{\prime}\left(D_{0}\right)\right) t}
$$

with

$$
f^{\prime}\left(D_{0}\right)>f^{\prime}\left(k_{1}^{s}\right)=\rho+\delta
$$

and

$$
C_{t} \rightarrow+\infty \quad \text { if } \quad t \rightarrow+\infty
$$


The optimal $\left(C_{t}, D_{t}\right)$ must intersect the curve $(\delta)$ (corresponding to $\dot{D}=0$, see fig. 1) at some date $T$. But when $t \geq T, D_{t}$ will decrease and this is in contradiction with corollary 1 . Then if $D_{t}$ is increasing, it must reach $k_{3}$ at some date $T$. Assume now that $D_{t}$ is decreasing. We have $D_{t} \leq D_{0}, \forall t$. If $D_{t}>k_{1}^{s}, \forall t$, since $\frac{d D}{d t} \leq 0$, we have

$$
C_{t} \geq \phi\left(D_{t}\right)+r D_{t}>\phi\left(k_{1}^{s}\right)+r k_{1}^{s}
$$

Starting from $D_{0}>k_{1}^{s}$, we have therefore :

$$
\frac{d D}{d t} \leq \phi\left(D_{0}\right)+r D_{0}-C_{t} \leq \phi\left(D_{0}\right)+r D_{0}-\phi\left(k_{1}^{s}\right)-r k_{1}^{s}<0
$$

and

$$
D_{t}-D_{0}<\left[\phi\left(D_{0}\right)+r D_{0}-\phi\left(k_{1}^{s}\right)-r k_{1}^{s}\right] t
$$

which implies $D_{t} \rightarrow-\infty$ : a contradiction. There exists $T$ such that $D_{T}=k_{1}^{s}$. We may have $\left(C_{t}, D_{t}\right)=\left(c_{1}^{s}, k_{1}^{s}\right), \forall t \geq T$, or $D_{t}$ continues decreasing for $t \geq T$. In the latter case, $D_{t}$ converges to 0. $C_{t}$ converges also, in this case, to 0 (proposition 6).

2. Using the same arguments, we obtain the conclusions stated in part 2 of theorem 1.

Remark 2 Consider now trajectories verifying the Euler-Lagrange and state equations. We may have many features : a trajectory may "collapse", may reach $k_{3}$ and "jump" on the stable manifold, may also, and this point is interesting, fluctuate, i.e., $D_{t}$ begins to increase, then decreases, and increases again, .... (figure 2).

(Insert figure 2)

\section{Remark 3 Comparison with the classical case.}

Assume that $f$ is concave verifying $f(0)=0, f^{\prime}(0)>\rho+\delta$. It is easy to check that with $f^{\prime}\left(k_{2}\right)=r+\delta$

$$
\begin{array}{lll}
\phi(D)=f(D)-(\delta+r) D & \text { if } & D \leq k_{2} \\
\phi(D)=f\left(k_{2}\right)-(\delta+r) k_{2} & \text { if } & D \geq k_{2} .
\end{array}
$$


Hence,

$$
\begin{gathered}
\phi(D)+r D=f(D)-\delta D \quad \text { if } \quad D \leq k_{2} \\
\phi(D)+r D=f\left(k_{2}\right)-(\delta+r) k_{2}+r D \quad \text { if } \quad D \geq k_{2} .
\end{gathered}
$$

$\phi(D)+r D$ is continuously differentiable and concave. There exists a unique steady state $k^{s}, f^{\prime}\left(k^{s}\right)=\rho+\delta$. Assume $u^{\prime}(0)=+\infty, \lim _{c \rightarrow 0} \frac{u^{\prime}(c)}{u^{\prime \prime}(c)}=0$. Then the stable manifold will start from $(0,0)$. The phase diagram is as follows :

(Insert figure 3)

For every $0 \leq D_{0} \leq k^{s}$, there exists an optimal path which converges to the steady state. Non optimal trajectories will "collapse". There is no fluctuations as in the case where $f$ exhibits increasing returns for $D$ less than some value $k_{3}$, and decreasing returns when $D \geq k_{3}$.

Remark 4 Comparison with Dechert-Nishimura (1983).

In their paper, the optimal path either converges to 0 or converges to the high level steady state; in other words with the same technology, "poor" and "rich" countries could converge to same steady state. In our model, with the same technology, a "rich" country will converge to the high level steady state, a "poor country" could converge to the low level steady state.

\section{The cases where the debt constraint is not equal to zero}

In the previous parts we assumed $\bar{S}=0$, i.e., that the country can not borrow on international market. This hypothesis is obviously unrealistic, most Lower Developed Countries (LDC) contract foreign debts to finance their investments.

In this section we provide two approaches to the debt constraint $\bar{S}(k)=\bar{s}$, $\forall k ; \bar{S}(k)=-\nu k$ for $\nu \in] 0,1[$.

Case 1. Let $\bar{s}<0$ be given. From section 2, we see that the optimal program is unchanged but the feasible constraint becomes :

$$
C_{t}+\dot{D}_{t}=f\left(k_{t}\right)-(\delta+r) k_{t}+r D_{t}+r \bar{s}
$$


So, in the phase-diagram of figure 1 , the curve $\frac{d D}{d t}=0$ is vertically translated by $r \bar{s}$. We distinguish two cases:

i) if $-\bar{s}<\frac{1}{r}\left(f\left(k_{1}^{s}\right)-\delta k_{1}^{s}\right)$ then the optimal steady state is either $k_{1}^{s}$ or $k_{2}^{s}$ (see figures $1,4,5$ ) ;

ii) if $-\bar{s}>\frac{1}{r}\left(f\left(k_{1}^{s}\right)-\delta k_{1}^{s}\right)$ then the optimal path, as in the Ramsey model, converges to the steady state $k_{2}^{s}$ (see figure 6).

Consequently, if the foreign countries release the debt constraints, the LDC may reach the high development state.

Case 2. Assume $\bar{S}(k)=-\nu k$, with $0<\nu<1$. We have seen in section 2 that the program becomes :

$$
\begin{gathered}
\max _{\left(\widehat{C}_{t}, D_{t}, k_{t}\right)} \int_{0}^{\infty} \widehat{u}\left(\widehat{C}_{t}\right) e^{-\rho t} d t \\
\text { s.t. } \quad \dot{D}_{t}+\widehat{C}_{t}=\widehat{f}\left(k_{t}\right)-\left(\delta^{\prime}+r\right) k_{t}+r D_{t} \\
\widehat{C}_{t} \geq 0, D_{t} \geq k_{t} \geq 0, \forall t, \\
D_{0} \text { is given. }
\end{gathered}
$$

With

$$
\begin{gathered}
\widehat{C}_{t}=\frac{C_{t}}{1-\nu} \\
\widehat{f}(k)=\frac{1}{1-\nu} f(k) \\
\widehat{u}(\widehat{C})=u((1-\nu) \widehat{C}) \\
\delta^{\prime}+r=\frac{\delta+r}{1-\nu} .
\end{gathered}
$$

Mathematically, the program is quite similar to the one we studied in sections 2, 3 and 4; hence our previous analyses remain valid. But the steady states are now determined by the following relation :

$$
\frac{1}{1-\nu} f^{\prime}\left(k^{s}\right)=\rho+\delta^{\prime}=\frac{\rho+\delta+(r-\rho) \nu}{1-\nu}
$$


or :

$$
f^{\prime}\left(k^{s}\right)=\rho+\delta+(r-\rho) \nu .
$$

There will be two values $k_{1}^{s}<k_{2}^{s}$ which satisfy this relation ; $k_{1}^{s}$ is in the convex part of $f$, while $k_{2}^{s}$ is in the concave part. When $\nu \rightarrow 1, k_{1}^{s}$ will be smaller than $\bar{k}$ and, from our analyses in sections 2,3 and 4 , it will "disappear" as steady state of the optimal program (see proposition 8 ). In other words, if the foreign countries release the debt constraint ( $\nu$ is close to 1) then, as in case 1 , the LDC may reach the high level steady state. 


\section{A P P E N D I X}

Proof. of proposition 3.

Assume $D_{0}^{\prime}>D_{0}$. Let $\left(C_{t}, D_{t}\right)$ verify

$$
\begin{aligned}
& C_{t} \geq 0, D_{t} \geq 0, \forall t \\
& C_{t}+\dot{D}_{t}=\phi\left(D_{t}\right)+r D_{t}, \forall t \\
& D(0)=D_{0} .
\end{aligned}
$$

Let $D^{\prime}$ be a solution to

$$
C_{t}+\dot{D}_{t}^{\prime}=\phi\left(D_{t}^{\prime}\right)+r D_{t}^{\prime}
$$

and

$$
D^{\prime}(0)=D_{0}^{\prime}
$$

$D$ and $D^{\prime}$ are continuous. Since $D_{0}^{\prime}>D_{0}, D^{\prime}(t)>D(t)$ for $t \in[0, T[$. Assume $D^{\prime}(T)=D(T)$. Since $\phi$ is increasing, we have :

$$
\dot{D}_{t}^{\prime}>\dot{D}_{t}, \quad \forall t \in[0, T[
$$

and hence

$$
D^{\prime}(T)-D_{0}^{\prime}>D(T)-D_{0}
$$

which implies

$$
D^{\prime}(T)>D(T)+D_{0}^{\prime}-D_{0}>D(T)
$$

We have therefore

$$
D^{\prime}(t)>D(t), \forall t .
$$

$\left(C_{t}, D_{t}^{\prime}\right)$ are feasible paths with initial data $D_{0}^{\prime}$. Hence $U(C) \leq V\left(D_{0}^{\prime}, 0\right)$, for every $C_{t}$ feasible from $D_{0}$, and $V\left(D_{0}, 0\right) \leq V\left(D_{0}^{\prime}, 0\right)$.

Proof. of proposition 4. 
$\dot{D}_{t}$ has constant $\operatorname{sign}$ in $\left[t_{0}-\varepsilon, t_{0}\left[\right.\right.$ for some $\varepsilon>0$. We have, for $\left.\left.\varepsilon^{\prime} \in\right] 0, \varepsilon\right]$,

$$
V\left(D\left(t_{0}-\varepsilon^{\prime}\right), 0\right)=\int_{0}^{\varepsilon^{\prime}} e^{-\rho t} u\left(C_{t+t_{0}-\varepsilon^{\prime}}\right) d t+e^{-\rho \varepsilon^{\prime}} V\left(D\left(t_{0}\right), 0\right)
$$

by the maximum principle.

Since $\mathrm{C}$ is bounded in $\left[t_{0}-\varepsilon^{\prime}, \varepsilon\right]$, we have $V\left(D\left(t_{0}-\varepsilon^{\prime}\right), 0\right) \rightarrow V\left(D\left(t_{0}\right), 0\right)$ when $\varepsilon^{\prime} \rightarrow 0$. By the same way, $V\left(D\left(t_{0}+\varepsilon\right), 0\right) \rightarrow V\left(D\left(t_{0}\right), 0\right)$ when $\varepsilon \rightarrow 0$.

\section{Proof. of proposition 5 .}

Let us recall that $C_{t}=\phi\left(D_{t}\right)+r D_{t}-\dot{D}_{t}$. Since $D$ is continuous and $\dot{D}$ is piecewise continuous on $\left[T, T^{\prime}\right]$ and $u^{\prime}(0)=+\infty$ we have $C_{t} \geq \alpha>0, \forall t \in$ $\left[T, T^{\prime}\right]$, for some $\alpha$. Let $h$ be piecewise $C^{1}$ on $\left[T, T^{\prime}\right]$ with $h(T)=h\left(T^{\prime}\right)=0$. Let $T_{i}$ be the intervals in $\left[T, T^{\prime}\right]$ on which $\dot{D}$ is continuous. There exists $\varepsilon>0$ such that

$$
\max _{i} \sup _{t \in T_{i}}\{|h(t)|+|\dot{h}(t)|\} \leq \varepsilon \Rightarrow \phi\left(D_{t}+h_{t}\right)+r\left(D_{t}+h_{t}\right)-\dot{D}_{t}-\dot{h}_{t}>0 \forall t \in\left[T, T^{\prime}\right] .
$$

Let $\lambda \in \mathbb{R}$. Define

$$
\theta_{h}(\lambda)=\int_{T}^{T^{\prime}} u(\phi(D+\lambda h)-r(D+\lambda h)-(\dot{D}+\lambda \dot{h})) e^{-\rho t} d t
$$

$\theta$ is differentiable at $\lambda=0$. We have :

$$
\begin{array}{r}
\int_{0}^{\infty} u(\phi(D+\lambda h)-r(D+\lambda h)-(\dot{D}+\lambda \dot{h})) e^{-\rho t} d t-\int_{0}^{\infty} u(\phi(D)+r D-\dot{D}) e^{-\rho t} d t \\
=\theta_{h}(\lambda)-\theta_{h}(0) .
\end{array}
$$

If $\lambda$ is sufficiently small, $\theta_{h}(\lambda) \leq \theta_{h}(0)$. Hence $\theta_{h}^{\prime}(0)=0$; this implies :

$$
\int_{T}^{T^{\prime}}\left[u^{\prime}\left(C_{t}\right)\left(\phi^{\prime}(D)+r\right) h-u^{\prime}\left(C_{t}\right) \dot{h}\right] e^{-\rho t} d t=0 .
$$

Let

$$
\psi(t)=\int_{T}^{t} u^{\prime}\left(C_{s}\right)\left(\phi^{\prime}\left(D_{s}\right)+r\right) e^{-\rho s} d s, t \in\left[T, T^{\prime}\right]
$$

and

$$
a(t)=\psi(t)+K
$$

where $K$ is defined by

$$
\int_{T}^{T^{\prime}}\left[u^{\prime}\left(C_{s}\right) e^{-\rho s}+\psi(s)\right] d s+K\left(T^{\prime}-T\right)=0 .
$$


Now,

$$
\begin{aligned}
\int_{T}^{T^{\prime}}\left[u^{\prime}\left(C_{t}\right)\left(\phi^{\prime}\left(D_{t}\right)+r\right)\right] h e^{-\rho t} d t & =\int_{T}^{T^{\prime}} a^{\prime}(t) h(t) d t \\
& =-\int_{T}^{T^{\prime}} a(t) h^{\prime}(t) d t
\end{aligned}
$$

since $h(T)=h\left(T^{\prime}\right)=0$.

(5) becomes :

$$
-\int_{T}^{T^{\prime}}\left(a(t)+u^{\prime}\left(C_{t}\right) e^{-\rho t}\right) \dot{h}(t) d t=0
$$

for every $h$, piecewise $C^{1}$ verifying $h(T)=h\left(T^{\prime}\right)=0$.

Now, take

$$
h=-\int_{T}^{t}\left(u^{\prime}\left(C_{s}\right) e^{-\rho s}+\psi(s)\right) d s-K(t-T), t \leq T^{\prime} .
$$

One gets, from (6) and the very definitions of $a$ and $K$ :

$$
\int_{T}^{T^{\prime}}\left(a(t)+u^{\prime}\left(C_{t}\right) e^{-\rho t}\right)^{2} d t=0
$$

Hence

$$
a(t)=-u^{\prime}\left(C_{t}\right) e^{-\rho t}, \text { for } t \in\left[T, T^{\prime}\right] .
$$

Since $a$ is continuous on $\left[T, T^{\prime}\right], C$ is also continuous on this interval. $\dot{a}$ is also continuous, and

$$
\dot{a}(t)=u^{\prime}\left(C_{t}\right)\left(\phi^{\prime}\left(D_{t}\right)+r\right) e^{-\rho t}=-\frac{d}{d t}\left(u^{\prime}\left(C_{t}\right) e^{-\rho t}\right)
$$

which is Euler-Lagrange equation.

Since $C_{t}=\phi\left(D_{t}\right)+r D_{t}-\dot{D}_{t}, \dot{D}$ is also continuous on $\left[T, T^{\prime}\right]$.

\section{Proof. of proposition 10.}

Let $D_{0}=\bar{D}$. If the optimal path is decreasing between 0 and $T$ where $T$ is defined by $D_{T}=\bar{k}$, then we have the following equations

$$
\dot{D}_{t}+C_{t}=\lambda\left(D_{t}-\bar{k}\right)+f(\bar{k})-\delta D_{t}
$$




$$
-\frac{d}{d t}\left(u^{\prime}\left(C_{t}\right) e^{-\rho t}\right)=e^{-\rho t} u^{\prime}\left(C_{t}\right)(\lambda-\delta) .
$$

Integrating (8) one gets :

$$
C_{t}=C_{0} e^{\frac{\rho-\lambda+\delta}{\sigma-1}} t
$$

Integrating (7) we have, with $f(\bar{k})=(r+\delta) \bar{k}$ :

$$
\begin{aligned}
D_{t}=D_{0} e^{(\lambda-\delta) t} & +\frac{r+\delta-\lambda}{\delta-\lambda} \bar{k}\left(1-e^{(\lambda-\delta) t}\right) \\
& -e^{(\lambda-\delta) t} C_{0}\left(\frac{\sigma-1}{\rho-\sigma(\lambda-\delta)}\right)\left(e^{\frac{\rho-\sigma(\lambda-\delta)}{\sigma-1} t}-1\right) .
\end{aligned}
$$

Let $V(D, 0)$ denote the value function. We have as in proposition 4 :

$$
V\left(D_{0}, 0\right)=\int_{0}^{T} u\left(C_{t}\right) e^{-\rho t} d t+e^{-\rho T} V(\bar{k}, 0) .
$$

$T$ must verify :

$$
\frac{d}{d t}\left(\int_{0}^{T} u\left(C_{t}\right) e^{-\rho t} d t\right)-\rho e^{-\rho T} V(\bar{k}, 0)=0 .
$$

Tedious computations yield (as in the proof of proposition 6) :

$$
e^{\rho T} \frac{d}{d t}\left(\int_{0}^{T} u\left(C_{t}\right) e^{-\rho t} d t\right)=u\left(C_{T}\right)+u^{\prime}\left(C_{0}\right) \dot{D}_{T} e^{(\rho-(\lambda-\delta)) T}
$$

with

$$
\dot{D}_{T}=r \bar{k}-C_{0} e^{\frac{\rho-\lambda+\delta}{\sigma-1} T} \text {. }
$$

Using (9) and substituting in (11) $C_{t}$ by its expression, we obtain :

$$
\rho V(\bar{k}, 0)=C_{0}^{\sigma}\left(\frac{1}{\sigma}-1\right) e^{\left(\frac{\rho-\lambda+\delta}{\sigma-1}\right) \sigma T}+C_{0}^{\sigma-1} r \bar{k} e^{(\rho-\lambda+\delta) T} .
$$

Since $\dot{D}(0)<0$, we have :

$$
(\lambda-\delta) D_{0}+(r+\delta-\lambda) \bar{k}-(\lambda-\delta) C_{0}<0 .
$$

Hence when $D_{0} \rightarrow+\infty$, then $C_{0} \rightarrow \infty$.

From (13), we have also $T \rightarrow+\infty$, and $C_{0} e^{\left(\frac{\rho-\lambda+\delta}{\sigma-1}\right) T}$ is bounded.

Let us go back to (10) and take $t=T$. Then : 


$$
\begin{aligned}
\bar{k} & =D_{0} e^{(\lambda-\delta) T}+\frac{r+\delta-\lambda}{\delta-\lambda} \bar{k}\left(1-e^{(\lambda-\delta) T}\right) \\
& -e^{(\lambda-\delta) T} C_{0}\left(\frac{\sigma-1}{\rho-\sigma(\lambda-\delta)}\right)\left(e^{\frac{\rho-\sigma(\lambda-\delta)}{\sigma-1} T}-1\right),
\end{aligned}
$$

or

$$
\begin{aligned}
\bar{k} e^{(\delta-\lambda) T} & =D_{0}+\frac{r+\delta-\lambda}{\lambda-\delta} \bar{k}+\frac{r+\delta-\lambda}{\delta-\lambda} \bar{k} e^{(\delta-\lambda) T} \\
& -C_{0}\left(\frac{\sigma-1}{\rho-\sigma(\lambda-\delta)}\right)\left(e^{\frac{\rho-\sigma(\lambda-\delta)}{\sigma-1} T}-1\right)
\end{aligned}
$$

Observe that $\rho-\sigma(\lambda-\delta)>\rho-\lambda+\delta>0$ and therefore $C_{0} e^{\frac{\rho-\sigma(\lambda-\delta)}{\sigma-1} T}$ is bounded since $C_{0} e^{\frac{\rho-\lambda+\delta}{\sigma-1} T}$ is also bounded.

From (14) we have

$$
k e^{(\delta-\lambda) T}<C_{0}+C_{0} \frac{\sigma-1}{\rho-\sigma(\lambda-\delta)}+C_{0} \frac{1-\sigma}{\rho-\sigma(\lambda-\delta)} e^{\frac{\rho-\sigma(\lambda-\delta)}{\sigma-1} T} .
$$

We have

$$
1+\frac{\sigma-1}{\rho-\sigma(\lambda-\delta)}=\frac{\rho-\sigma(\lambda-\delta)+\sigma-1}{\rho-\sigma(\lambda-\delta)} .
$$

Hence, if $\rho<1-\sigma+\sigma(\lambda-\sigma)$, the second member of (15) goes to $-\infty$ when $C_{0} \rightarrow+\infty$ : a contradiction. 


\section{References}

[1] Azariadis, C. (1996), "The Economics of Poverty Traps. Part One : Complete Markets", Journal of Economic Growth, 1, pp 449-486.

[2] Azariadis, C., A. Drazen (1990), "Threshold Externalities in Economic Development", Quarterly Journal of Economics, 105, pp 501-526.

[3] Barro, R., X. Sala-i-Martin (1995), Economic Growth, McGraw Hill, New York.

[4] Barro, R.J., M.G. Mankiw, X. Sala-i-Martin (1995), "Capital Mobility in Neoclassical Models of Growth", American Economic Review, pp 103115.

[5] Carlson, D.A., A.B. Haurie, A. Leizarowitz (1991), Infinite Horizon Optimal Control, Springer-Verlag, Berlin.

[6] Cohen, D., J.D. Sachs (1986), "Growth and External Debt under Risk of Debt Repudiation", European Economic Review, 30 (3), pp 1138-54.

[7] Dechert, W.D., K. Nishimura (1983), "A Complete Characterization of Optimal Growth Paths in an Aggregated Model with Non-Concave Production Function", Journal of Economic Theory, 31, pp 332-354.

[8] van de Klundert, T., S. Smulders (1996), "North-South Knowledge spillovers and competition : convergence versus divergence", Journal of Development Economics, 50, pp 213-232.

[9] Krugman, P. (1991), "History versus Expectations", Quarterly Journal of Economics, 106, pp 651-667.

[10] Léonard, D., N. Van Long (1992), Optimal Control Theory and Static Optimization in Economics, Cambridge University Press, Cambridge.

[11] Young, A. (1991), "Learning by Doing and the Dynamic Effects of International Trade", Quarterly Journal of Economics, 106, pp 369-405.

[12] Young, A. (1995), "The Tyranny of Numbers : Confroncting the Statistical Realities of the East Asian Growth Experience", Quarterly Journal of Economics, 110, pp 641-680. 


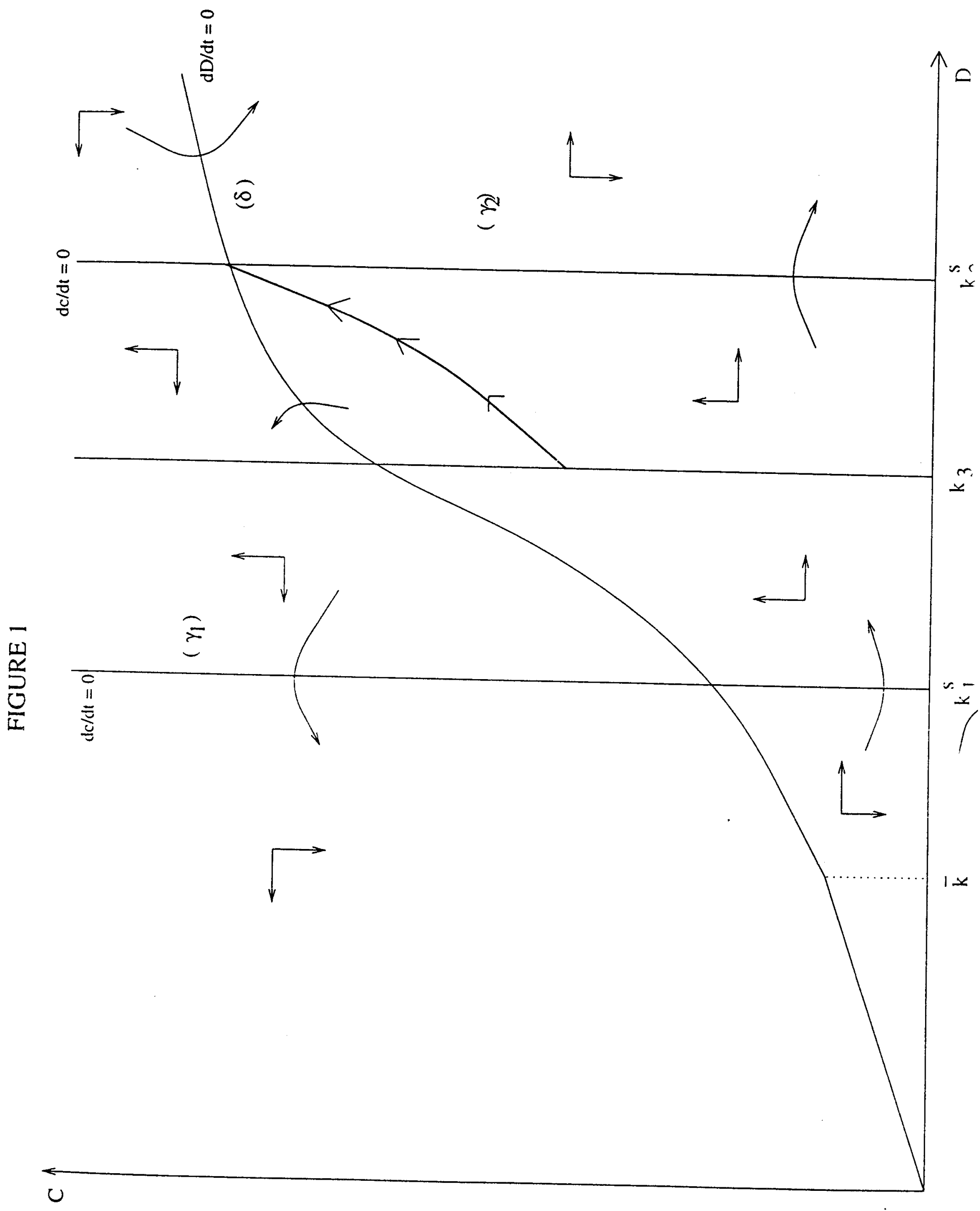




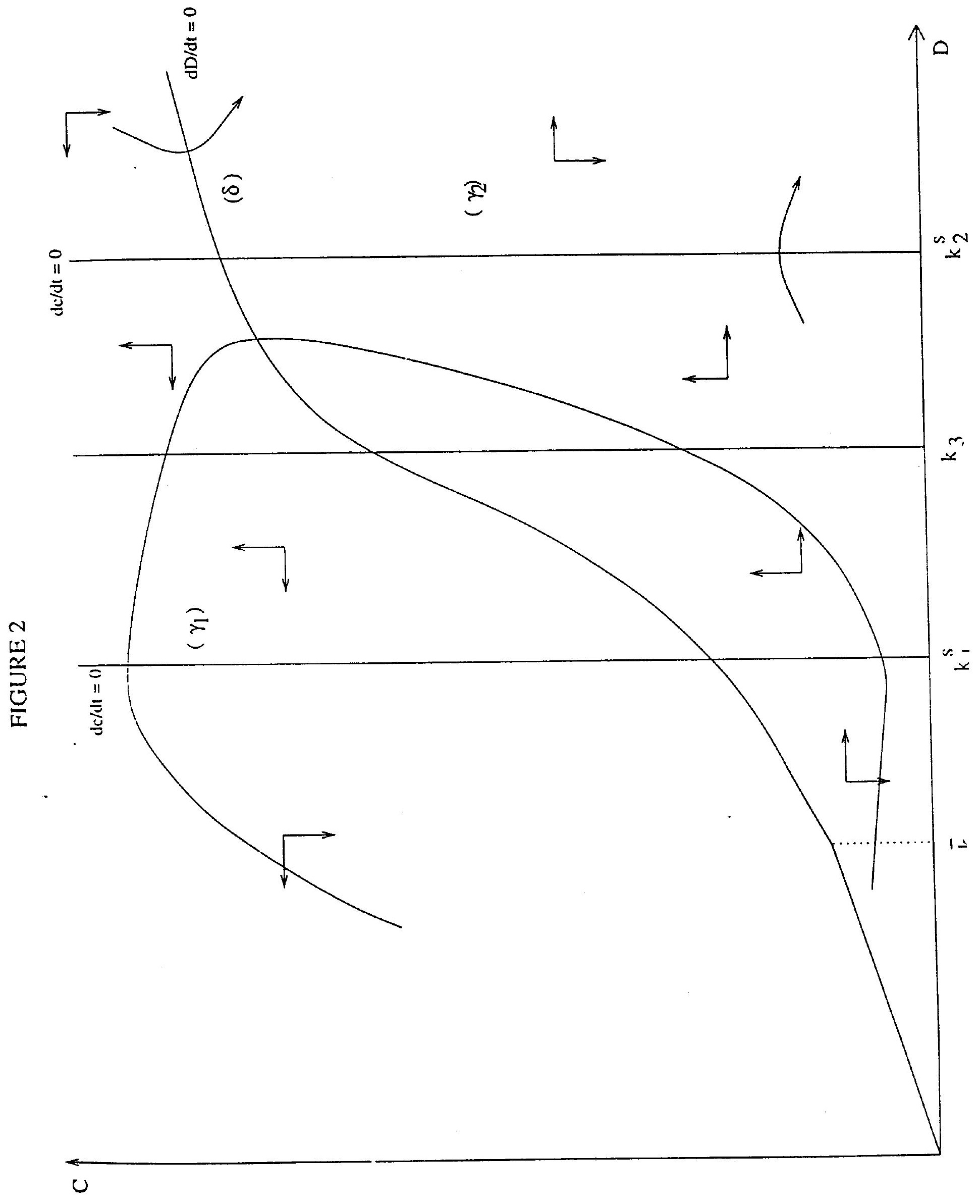


FIGURE 3

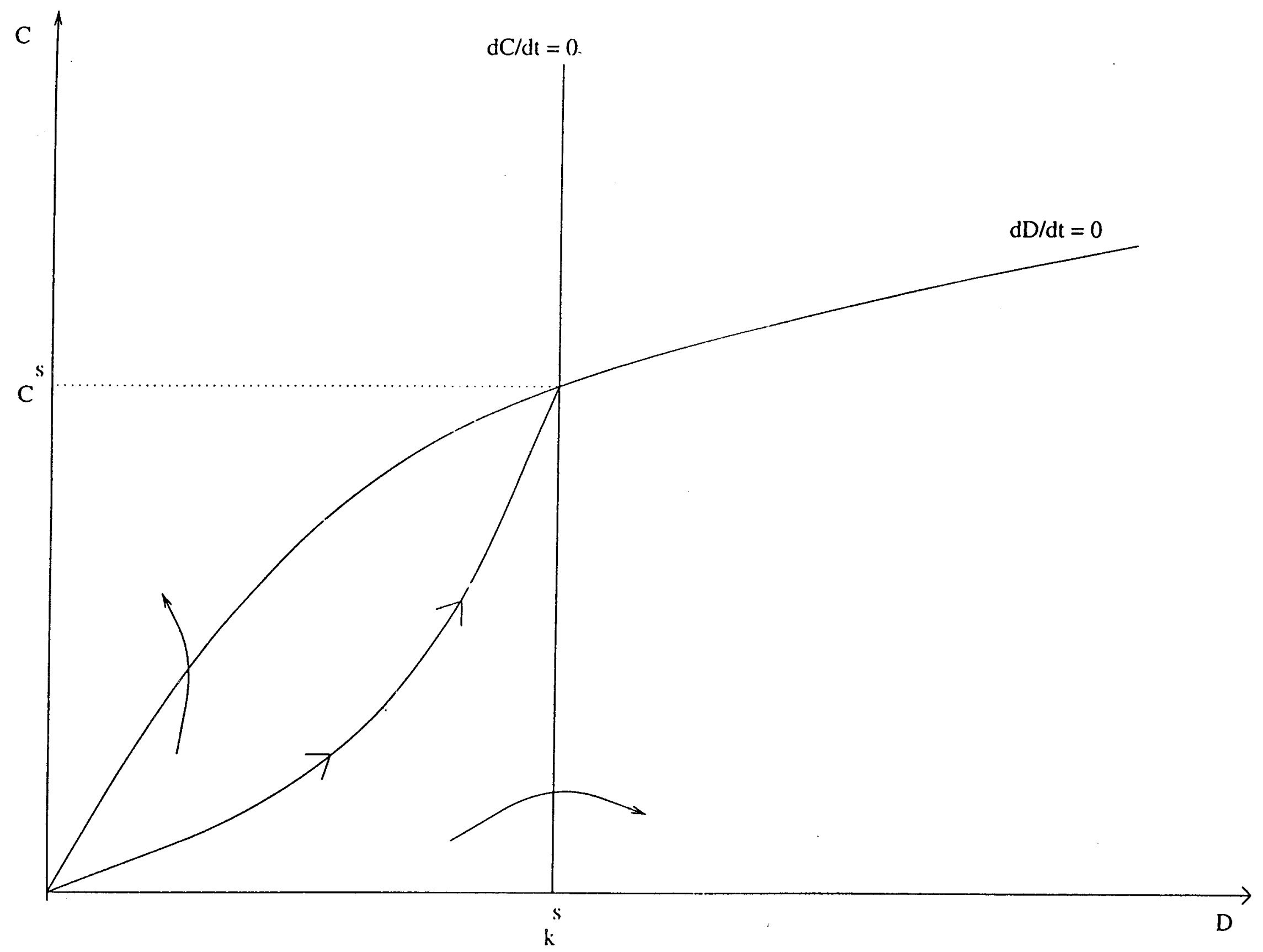


FIGURE 4

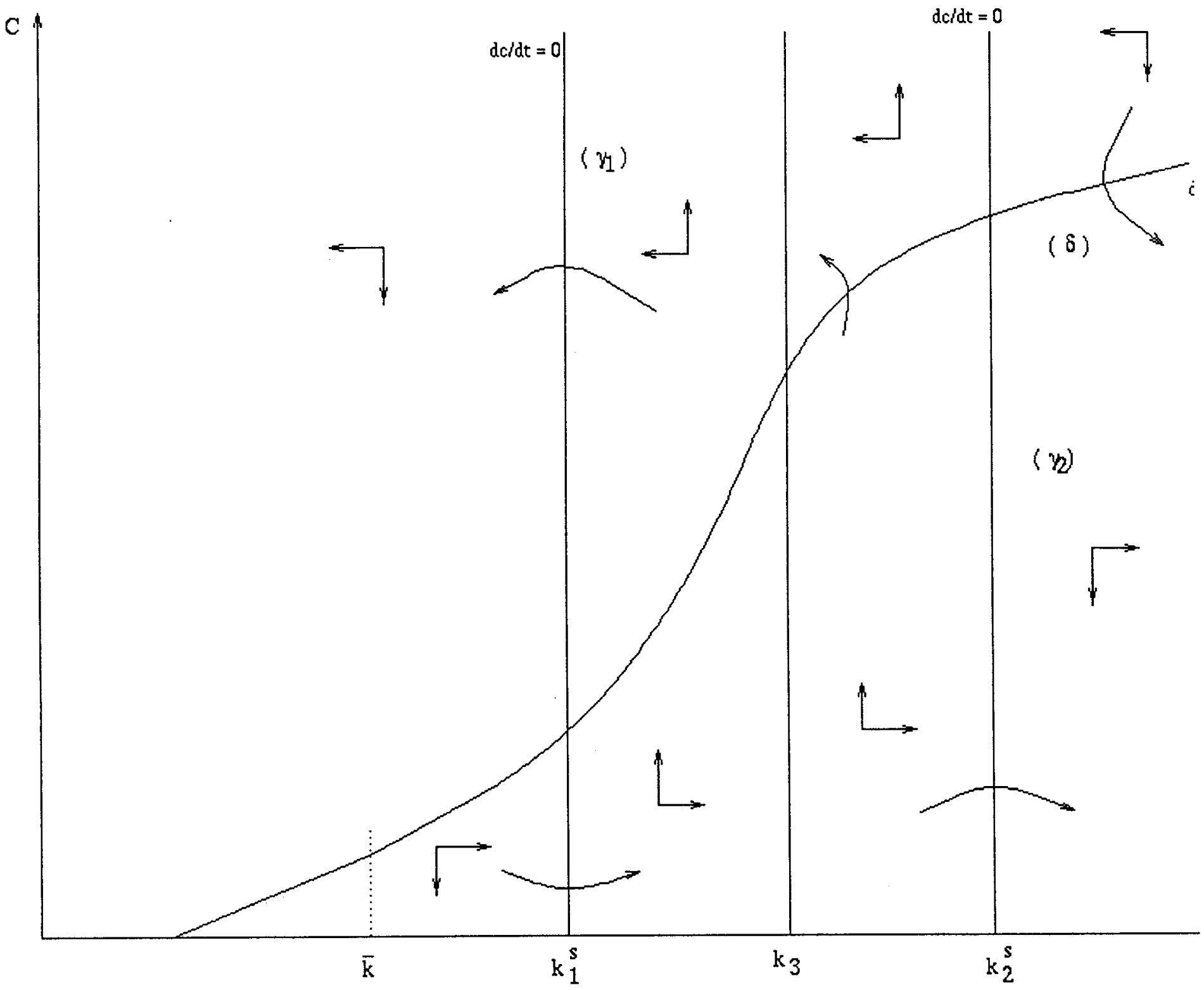


FIGURE 5

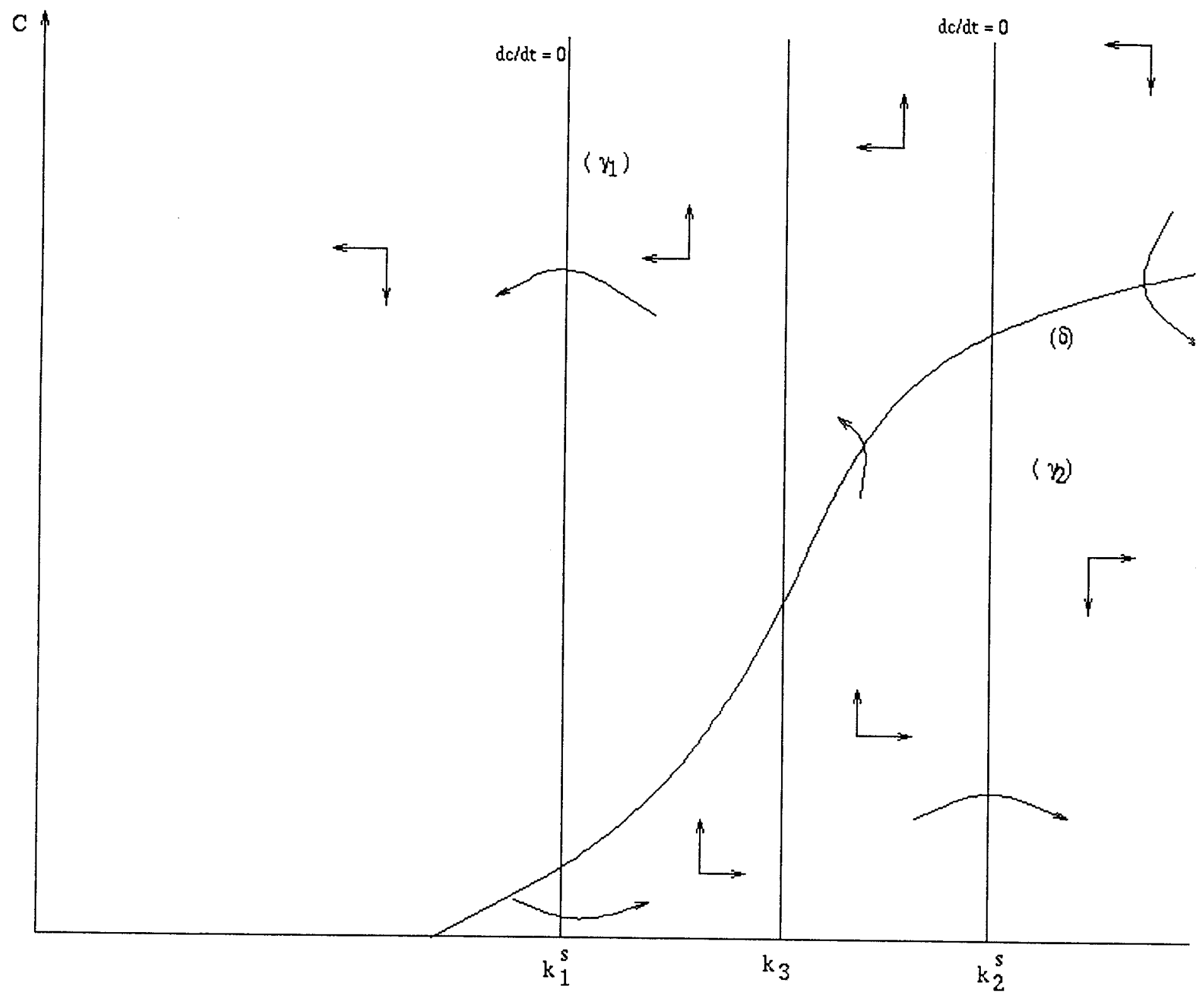


FIGURE 6

c

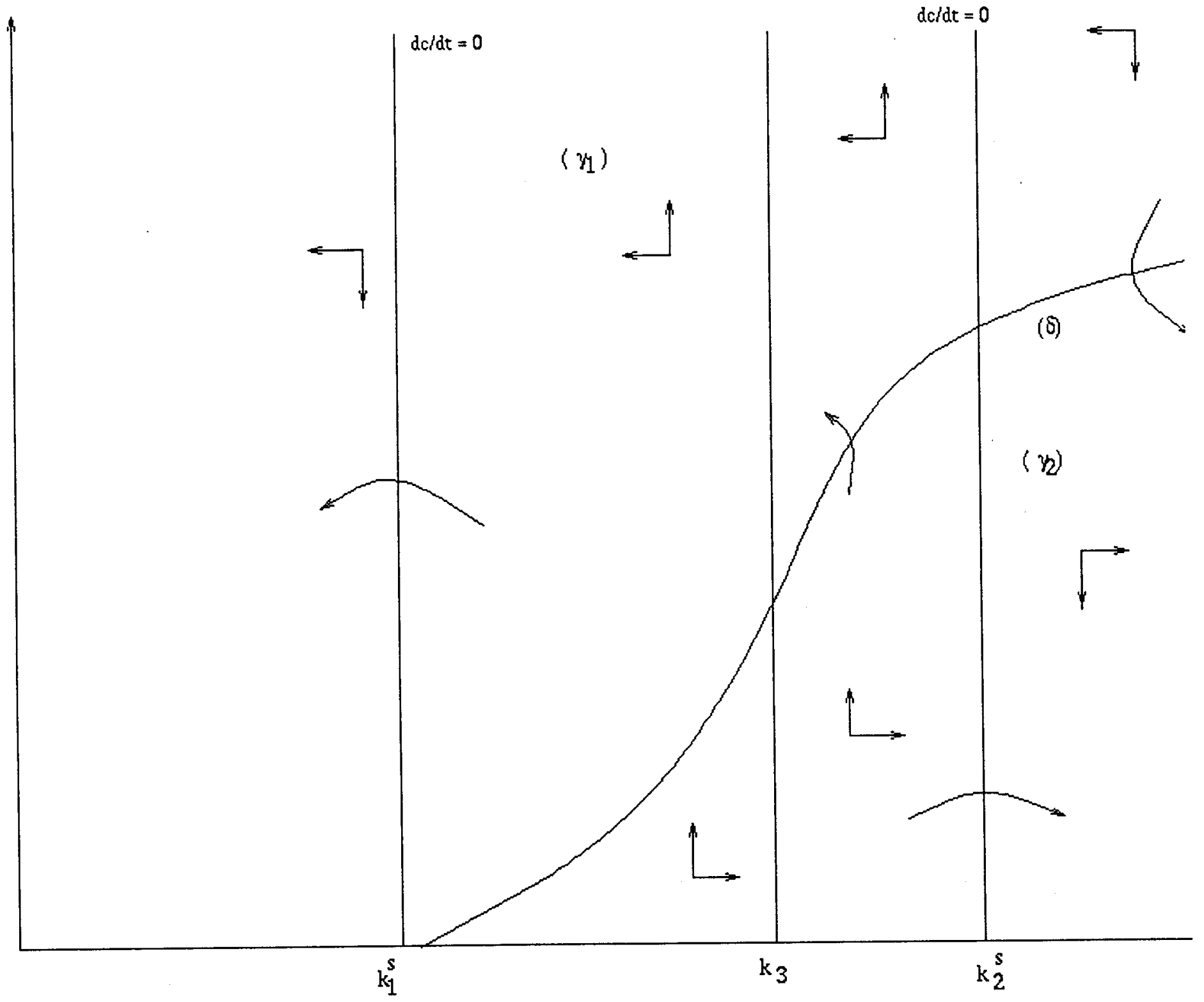

